\title{
CFD Analysis of Oxygen and Carbon Dioxide Recovery during Ventilation in Municipal Confined Space
}

\author{
Yan Liu, Cong Tan, Dongliang Liu \\ Beijing Municipal Institute of Labour Protection, Beijing 100054, China \\ E-mail:liuyandhn@163.com
}

Received 31 August 2016

Accepted 23 September 2016

\begin{abstract}
Confined space is a special working place. To ensure the safety, the forced ventilation must be carried out before entering the confined space. In this paper, ventilation process in municipal heating confine space is simulated by CFD numerical simulation method, and the distribution of temperature, oxygen and carbon dioxide in municipal heating confined space during ventilation process is studied. The simulation results show that the airflow and temperature are obviously stratified in vertical direction during the ventilation. The temperature is low and the airflow velocity is high at the bottom part of the tunnel. While the temperature is high and the airflow velocity is low at the top of the tunnel. By contrast, recovery of the oxygen and carbon dioxide content is relatively faster at the bottom than it at the top. When the ventilation volume flow rates are $6000 \mathrm{~m}^{3} \cdot \mathrm{h}^{-1}, 8000 \mathrm{~m}^{3} \cdot \mathrm{h}^{-1}, 10000 \mathrm{~m}^{3} \cdot \mathrm{h}^{-1}$, $12000 \mathrm{~m}^{3} \cdot \mathrm{h}^{-1}$, and $14000 \mathrm{~m}^{3} \cdot \mathrm{h}^{-1}$ respectively, the time when the temperature reach stable and gas fraction return to normal are 45 minutes, 32 minutes, 22 minutes, 15 minutes, 10 minutes respectively.
\end{abstract}

Keywords: CFD; numerical simulation; municipal confined space; ventilation; oxygen content

\section{Introduction}

According to the definition of the Occupational Safety and Health Administration of the United States, the confined space is defined as ${ }^{1}:(1)$ is large enough and so configured that an employee can bodily enter and perform assigned work; (2) has limited or restricted means for entry or exit; and(3) is not designed for continuous employee occupancy. Municipal heating pipe tunnel belongs to confined space. Because of longterm closure and poor natural ventilation, worker will suffer hypoxia phenomenon when performing some operations in $\mathrm{it}^{2}$.

Many countries focus on the safety of the confined space operations. The United States ${ }^{3}$, Britain ${ }^{4}$, France ${ }^{5}$, Australia $^{6}$ and other countries have developed a number of standards for confined space operations. NIOSH has made a thorough research on the safety of the confined space, and published a series of safety publications about the confined space operations. For example, Criteria for a Recommended Standard, Working in Confined Spaces ${ }^{7}$, Request for Assistance in Preventing Occupational Fatalities in Confined Spaces ${ }^{8}$ and A Guide to Safety in Confined Spaces ${ }^{9}$, which play a positive role in the prevention of the confined space accident. Great attention is also paid to the safety of the confined space working in China. Gao ${ }^{10}$,Fan ${ }^{11}$, Zhong ${ }^{12}$, Chen ${ }^{13}$ and other researchers have carried out some research on the hazard identification, accident prevention, control measures, supervision and management of the confined space.

The current research results show that there may be hydrogen sulfide, Ammonia, methane and other toxic, flammable or explosive gas in the atmosphere of confined space, and oxygen deficiency in very common. Oviedo $^{14}$ studied concentration and distribution of hydrogen sulfide in sewer system. J M Santos ${ }^{15}$, V. Blanes-Vidal ${ }^{16}$ studied the production rate of $\mathrm{NH}_{3}, \mathrm{CO}_{2}$, 
$\mathrm{H}_{2} \mathrm{~S}$ respectively. $\mathrm{Mi}^{17}$, Peng ${ }^{18}$ studied the accumulation of combustible gas in sewage in the mechanism, and the gas evaluation model of explosion risk of city sewers and septic tanks as well as the warning model of gas explosion are built. Wang, Bao ${ }^{19}$ designed a remote monitoring and early warning system for municipal sewer harmful gas based on infrared sensor technology and GPRS wireless data transmission so as to realize the function of real-time monitoring and monitoring of the concentration of combustible gas in municipal sewage.

Confined space operation procedure issued by the United States Occupational Safety and Health Department requires that before entering the confined space, the concentration of oxygen, toxic gases and flammable gas must be detected. Also, no one is accessed to entering the confined space before eliminating the harmful gas by forced ventilation. Standard titled Interim Provisions on the Safety Management and Supervision of the Limited Space Operation of Industry and Trade Enterprises issued in 2013 by State Administration of Work Safety puts forward that the confined space operations should strictly abide by the principle of "ventilation first, reinspection second, and operations last", which is reemphasized in standard titled Five Provisions on the Safety Operation of Confined Space issued in 2014 requiring that no operation should be carried out if there is no ventilation or monitor result are not up to standard. In conclusion, the forced ventilation is an essential step to ensure the safety of the workers before entering the confined space.

CFD numerical simulation method has been widely used in the study of gas flow and mixed gas distribution. M.Siddiqui ${ }^{20}$ studied risk control and assessment of indoor heavy gas leakage using CFD method. S.G. Giannissi ${ }^{21}$ studied the hydrogen leakage and diffusion in the confined space under the condition of natural ventilation using CFD method. Zhao ${ }^{22}$ optimized ventilation scheme in the septic tank confined space using CFD method. In this paper, the process of forced ventilation in heating confined space is simulated using CFD method. And the recovery law of temperature, oxygen, and carbon dioxide under different ventilation condition is obtained, which can provide theoretical basis and technical support for forced ventilation before operation.

\section{Basic Equations of Numerical Simulation}

Because the maximum air flow speed in the process of ventilation is far lower than the speed of sound $(340 \mathrm{~m} \cdot \mathrm{s}$ ${ }^{1}$ ), so the air in municipal heating confined space can be regarded as an incompressible fluid. And the ventilation process belongs to unsteady single-phase multicomponent diffusion issues without chemical reaction, so the flow is governed by the conservation of mass, momentum, and energy balance and species transmission equation in CFD. The multi-component three-dimensional unsteady turbulent flow is described by equations (1), (2), (3), (4) and (5) respectively.

Mass conservation equation (also known as continuity equation):

$$
\frac{\partial \rho}{\partial t}+\frac{\partial}{\partial x_{\mathrm{i}}}\left(\rho u_{\mathrm{i}}\right)=0
$$

Momentum balance equation:

$$
\begin{aligned}
& \frac{\partial}{\partial t}\left(\rho u_{\mathrm{i}}\right)+\frac{\partial}{\partial x_{\mathrm{j}}}\left(\rho u_{\mathrm{i}} u_{\mathrm{j}}\right)=-\frac{\partial p}{\partial x_{\mathrm{i}}}+\frac{\partial \tau_{\mathrm{ij}}}{\partial x_{\mathrm{j}}}+\rho g_{\mathrm{i}}+F_{\mathrm{i}} ; \\
& \text { Energy equation: } \\
& \frac{\partial}{\partial t}(\rho E)+\frac{\partial}{\partial x_{\mathrm{i}}}\left[u_{\mathrm{i}}(\rho E+p)\right]= \\
& \frac{\partial}{\partial x_{\mathrm{i}}}\left(k_{\mathrm{eff}} \frac{\partial T}{\partial x_{\mathrm{i}}}-\sum J_{\mathrm{c}} \int_{T_{\text {ref }}}^{T} c_{\mathrm{pc}} d T+u_{\mathrm{i}}\left(\tau_{\mathrm{ij}}\right)_{\mathrm{eff}}\right)+S_{\mathrm{h}} \\
& E=\sum \omega_{\mathrm{c}} \int_{T_{\text {ref }}}^{T} c_{\mathrm{pc}} d T+\frac{v^{2}}{2}
\end{aligned}
$$

Species transmission equation:

$$
\frac{\partial}{\partial t}\left(\rho \omega_{\mathrm{c}}\right)+\frac{\partial}{\partial x_{\mathrm{i}}}\left(\rho u_{\mathrm{i}} \omega_{\mathrm{c}}\right)=\frac{\partial}{\partial x_{\mathrm{i}}}\left(\rho D_{\mathrm{c}} \frac{\partial \omega_{\mathrm{c}}}{\partial x_{\mathrm{i}}}\right)
$$

$k-\varepsilon$ turbulence equations:

$k$ equation:

$$
\frac{\partial}{\partial x_{\mathrm{i}}}\left(\rho u_{\mathrm{i}} k\right)=\frac{\partial}{\partial x_{\mathrm{i}}}\left[\left(\mu+\frac{\mu_{\mathrm{t}}}{\sigma_{\mathrm{k}}}\right) \frac{\partial k}{\partial x_{\mathrm{i}}}\right]+G_{\mathrm{k}}-\rho \varepsilon ;
$$

$\varepsilon_{-}$equation:

$$
\begin{array}{r}
\frac{\partial}{\partial x_{\mathrm{i}}}\left(\rho u_{\mathrm{i}} \varepsilon\right)=\frac{\partial}{\partial x_{\mathrm{i}}}\left[\left(\mu+\frac{\mu_{\mathrm{t}}}{\sigma_{\varepsilon}}\right) \frac{\partial k}{\partial x_{\mathrm{i}}}\right]+\frac{C_{\varepsilon 1} \varepsilon}{k} G_{\mathrm{k}}-C_{\varepsilon 2} \rho \frac{\varepsilon^{2}}{k} \\
\text { Where } \mu_{\mathrm{t}}=C_{\mu} \rho \frac{k^{2}}{\varepsilon}, G_{\mathrm{k}}=\mu_{\mathrm{t}} \frac{\partial u_{\mathrm{j}}}{\partial x_{\mathrm{i}}}\left(\frac{\partial u_{\mathrm{i}}}{\partial x_{\mathrm{j}}}+\frac{\partial u_{\mathrm{j}}}{\partial x_{\mathrm{i}}}\right) .
\end{array}
$$

Here, $\rho$ is the gas density, $\mathrm{kg} \cdot \mathrm{m}^{-3} ; v$ is the fluid velocity, $\mathrm{m} \cdot \mathrm{s}^{-1} ; u_{i}$ is the velocity component in the $i$ th direction, $\mathrm{m} \cdot \mathrm{s}^{-1} ; x_{i}$ is coordinate in the $i$ th direction, $\mathrm{m} ; p$ is the fluid pressure, $\mathrm{Pa} ; \tau_{i j}$ is the stress tensor, $\mathrm{N} \cdot \mathrm{m}^{-2} ; g_{i}$ is the component of gravitational acceleration in the ith direction, $\mathrm{N} \cdot \mathrm{kg}^{-1} ; F_{i}$ is external volume force in the ith direction, $\mathrm{N} ; E$ is a fluid energy, $\mathrm{J} ; k_{\text {eff }}$ is the effective 
thermal conductivity; $J c$ is the diffusion flux of component c; $S_{h}$ is the volume heat source; $\omega_{c}$ is the mass fraction of component $\mathrm{c} ; D_{c}$ is the diffusion coefficient of component $\mathrm{c} ; c_{p \mathrm{c}}$ is the specific heat capacity of component $\mathrm{c}, \mathrm{J} \cdot(\mathrm{kg} \cdot \mathrm{K})^{-1} ; k$ is the turbulent kinetic energy, $\mathrm{m}^{2} \cdot \mathrm{s}^{-2} ; \varepsilon$ is the turbulent kinetic energy dissipation rate, $\mathrm{m}^{2} \cdot \mathrm{s}^{-3} ; G_{k}$ is the rate of change of turbulent kinetic energy, $\mu \nu$ is the viscosity coefficient of laminar flow, $\mu_{t}$ is the coefficient of turbulent viscosity, $\mathrm{Pa} \cdot \mathrm{s}, C_{\varepsilon 1}, C_{\varepsilon 2}, C_{\mu}, \sigma_{\varepsilon}, \sigma_{k}, T_{r e f}$ are constants, taken as 1.44, $1.92,0.09,1.3,1.0,298.15 \mathrm{~K}$.

\section{Numerical Simulation Model}

\subsection{Geometric model}

A heating confined space in Beijing is selected to do the simulation. The heating chamber is 6 meters long, 5 meters wide and 6 meters high. The distance from the roof of the chamber to the floor (i.e. shaft deep) is 4 meters. Two entrance shafts locate at the diagonal of the chamber, and below the shaft, there is a metal platform and a metal ladder. There are arch pipe ditch which is 3 meters wide and 2.5 meters high on both sides of the chamber. In the pipe tunnel, there is a ventilation shaft with the diameter of $0.7 \mathrm{~m}$ which is 100 meters away from the chamber. Two diameters $0.8 \mathrm{~m}$ heating pipes (including thermal insulation layer) are built along the pipe tunnel. In the chamber, the heating pipe is divided into two branch pipes with the diameter of $0.6 \mathrm{~m}$ which pass through the side chamber. And the valves are installed at the interface. Because the platform, the ladder handrail, and the value structure of the pipeline are small, and they have little influence on the distribution of the flow field of the chamber, they are ignored to simplify the model and reduce the calculation. According to the actual situation, a threedimensional geometric model is built, as is shown in Fig.1.

The origin $(0,0,0)$ of the model is set at the center of the heating chamber floor. The $\mathrm{X}$ axis is along the tunnel, the $\mathrm{Y}$ axis is the horizontal direction vertical towards the tube groove and the vertical upward is set as the $\mathrm{Z}$ axis. 9 observation points are set and the coordinates are $\mathrm{V} 1(0,0,1), \mathrm{V} 2(0,0,3), \mathrm{V} 3(0,0,5.9)$, $\mathrm{V} 4(50,0,0.5), \quad \mathrm{V} 5(50,0,1), \mathrm{V} 6(50,0,1.9), \mathrm{V} 7(99,0,0.5)$, $\mathrm{V} 8(99,0,1)$, and $\mathrm{V} 9(99,0,1.9)$.

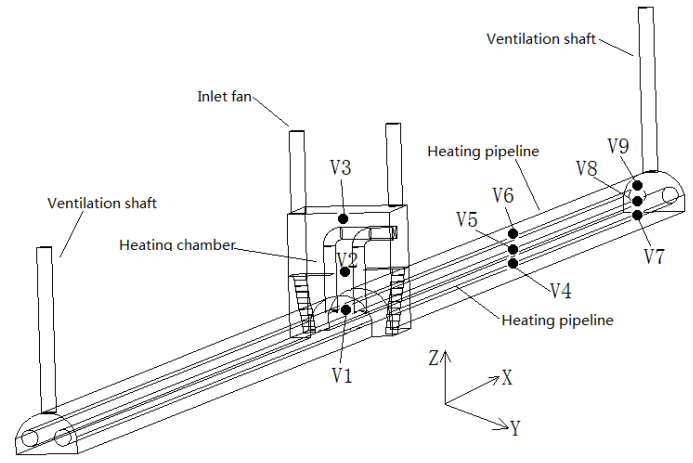

Fig.1. Geometric model of heating confined space.

\subsection{Simulation parameters}

In the boundary conditions setting, the ventilation rates are set as $6000,8000,10000,12000$ and $14000 \mathrm{~m}^{3} \cdot \mathrm{h}^{-1}$ respectively. So, according to area of the inlet, velocity inlet is set with the air flow velocity 4.33, 5.77, 7.22, 8.66 and $10.1 \mathrm{~m} \cdot \mathrm{s}^{-1}$ respectively. Outflow is set in the exit. The surface of the heating pipeline is set as the wall of heat source. And the temperature is $60^{\circ} \mathrm{C}$. Original gas content, internal temperature and other parameters are set according to the actual results of the field trial, which are shown in table 1 .

Table 1. Simulation parameters settings.

\begin{tabular}{cc}
\hline Name & Parameter Settings \\
\hline Solving Type & Unsteady \\
Energy Model & On \\
Turbulence Model & $k$ - $\varepsilon$ two-equation model \\
Component model & Component delivery model \\
The operating temperature $(\mathrm{K})$ & 288 \\
Acceleration of gravity $\left(\mathrm{m} \cdot \mathrm{s}^{-2}\right)$ & Z-axis direction: -9.81 \\
Operating pressure $(\mathrm{Pa})$ & 101325 \\
Type inlet boundary & Speed inlet \\
Inlet velocity $\left(\mathrm{m} \cdot \mathrm{s}^{-1}\right)$ & $4.33,5.77,7.22,8.66,10.1$ \\
& $\mathrm{O}_{2}: 20.9 \% ; \mathrm{N}_{2}: 78 \% ; \mathrm{CO}_{2}:$ \\
Inlet species fraction & $0.03 \% ; \mathrm{H}_{2} \mathrm{O}: 0.03 \% ;$ \\
& Other:1.07\% \\
Hydraulic diameter (m) & 0.7 \\
Turbulence intensity $(\%)$ & 2.6 \\
Outlet boundary type & Outflow \\
Wall temperature (K) & 333 \\
Pressure - velocity coupling & $\mathrm{SIMPLEC} \mathrm{Algorithm}$ \\
The initial value & $\mathrm{O}_{2}: 12 \% ; \mathrm{N}_{2} 81 \% ; \mathrm{CO}_{2}: 2 \% ;$ \\
Time step (s) & $\mathrm{H}_{2} \mathrm{O}: 2.5 \% ; \mathrm{Other:} 2.5 \%$ \\
Number of steps & 1 \\
Convergence precision & 3600 \\
\hline
\end{tabular}

The geometric model is imported to CFD software, and the parameters are set according to the Table 1 . The parallel computation is carried out using 32-nuclear 
work station. The result shows that the residual value (including continuous residual value, velocity residual value, energy residual value, $\mathrm{K}$ residual value, $\varepsilon$ residual value, and residual values of all species fraction) is less than 0.001 . Therefore, the calculation results can reach the convergence requirements.

\section{Numerical Simulation Results}

\subsection{Distribution of flow field}

In the process of ventilation, the distribution of flow field has a direct influence on the ventilation effect. At the beginning of the ventilation, the internal stationary gas starts to flow. The original gas distribution has great influence on the flow field. In order to avoid this effect, the flow field after 10 minutes ventilation (according to the simulation results, in the tunnel, the original gas distribution has no longer effect on the air flow field after 10 minutes) was selected to analyze. For example, when the ventilation volume flow rate is $6000 \mathrm{~m}^{3} \cdot \mathrm{h}^{-1}$, velocity vector diagram of airflow and airflow velocity contour of $\mathrm{X}$ cross section are shown in Fig. 2 and Fig. 3 respectively.

As is shown in Fig.2 and Fig.3, fresh air is driven vertically into the chamber when ventilation begins. Due to the block of the platform, the airflow diffuses to the central part of the chamber. The airflow forms a large eddy current in the chamber and the airflow velocity distribution is extremely uneven. The airflow at the central chamber is fast, and velocity can reach above $1 \mathrm{~m} \cdot \mathrm{s}^{-1}$. However, the airflow at the top and bottom of the chamber is slow, and velocity is only $0.1 \mathrm{~m} \cdot \mathrm{s}^{-1}$. Airflow direction change rapidly when the air flows from the chamber to the tunnel, and vortex is formed at the top of the pipe tunnel. Therefore, some airflow reverse at the top of tunnel within $10 \mathrm{~m}$ away from chamber. Airflow is relatively stable in the tunnel beyond $10 \mathrm{~m}$. Air flows mainly along the bottom of the tunnel to both sides of the ventilation shaft. The airflow velocity is less than $0.1 \mathrm{~m} \cdot \mathrm{s}^{-1}$ at the bottom of the tunnel. Hot air rise and accumulate at the top of the tunnel according to temperature field, which make air flow faster at the bottom of the tunnel than it at the bottom. The distribution of airflow velocity field directly affects the recovery time of oxygen content. Therefore, much attention should be paid to the oxygen content in the corner of both top and bottom of the chamber, as well as that in the top of the tunnel.

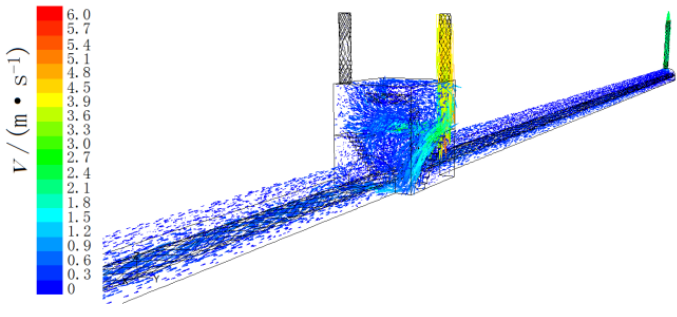

Fig.2. Velocity vector of airflow in tunnel.

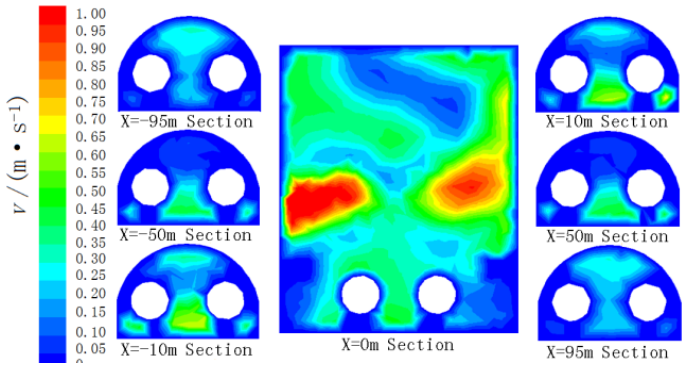

Fig.3. Airflow velocity contours of different cross sections along the pipe tunnel.

\subsection{Distribution of temperature}

The temperature of hot water or hot air inside the heating pipeline is as high as $140^{\circ} \mathrm{C}$.Although measures of heat preservation and heat insulation are used, heat is still transferred into the pipe ditch space. Surface temperature of the thermal insulation layer is about $60^{\circ} \mathrm{C}$ according to measurement. When the ventilation volume flow rate is $6000 \mathrm{~m}^{3} \cdot \mathrm{h}^{-1}$, temperature in different sections in the tunnel and chamber after 10 mins ventilation is shown in Fig. 4 and temperature change of different observation points is shown in Fig.5.

In fig.4, temperature decreases fast in the chamber during the process of ventilation. And temperature at middle area of the chamber is lower compared with it at the top and the bottom. That is because there is a turbulent area at the top of the chamber, and air flows more slowly at the top area than it at other area, which makes temperature decrease more slowly at the top area. At the bottom of the chamber, the heating pipe release heat continuously, so the air temperature around the pipe is relatively high, but the area is small. Temperature at the top of the tunnel is higher than it at the bottom of the tunnel. Temperature at the area above the heating pipe is $11{ }^{\circ} \mathrm{C}$ higher than that below the heating pipe. High temperature area around the heating pipe is large. Due to the effect of thermal lift, hot air rises up and accumulates at the top. Also, the distribution of temperature field also influences the 
distribution of airflow field. The air flows faster at the bottom compared with it at the top, which further aggravates the uneven distribution of the temperature field. Fig. 5 shows the temperature at each observation point decreases to a stable value after 25 minutes when the ventilation volume flow rate is $6000 \mathrm{~m}^{3} \cdot \mathrm{h}^{-1}$. Thereafter temperature in the space reaches a steady state and temperature at the observation point $(50,0$ , 1.9 ) is the highest, which is about $49{ }^{\circ} \mathrm{C}$. Temperature at the obviation point $(0,0,3)$ in the chamber is relatively low, which is $27^{\circ} \mathrm{C}$.

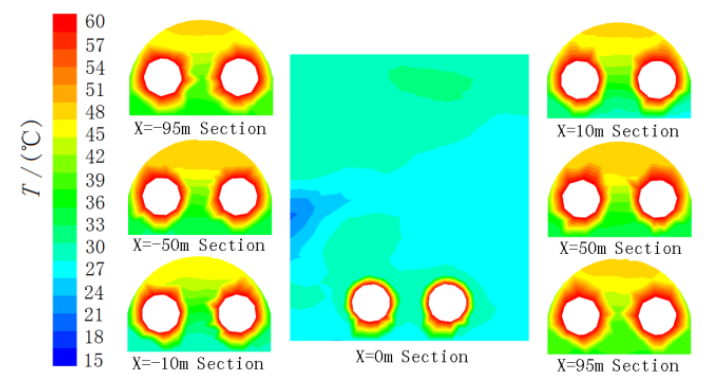

Fig.4. Temperature contours of different sections along the pipe tunnel.

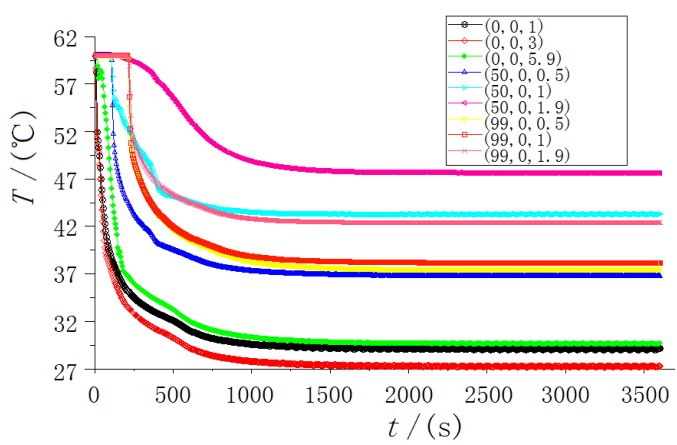

Fig.5. Temperature of different observation points as a function of time.

\subsection{Distribution of oxygen}

When ventilation volume flow rate is $6000 \mathrm{~m}^{3} \cdot \mathrm{h}^{-1}$, oxygen distributions of different cross sections after 10 mins ventilation in the chamber and the pipe tunnel are shown in Fig.6. Oxygen content distributions along the tunnel of different heights are shown in Fig.7. Oxygen content time histories of different observation points are shown in Fig.8.

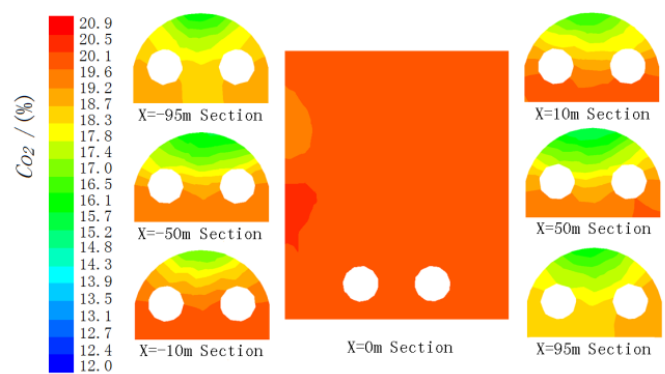

Fig.6. Oxygen content contours of different cross sections along the tunnel.

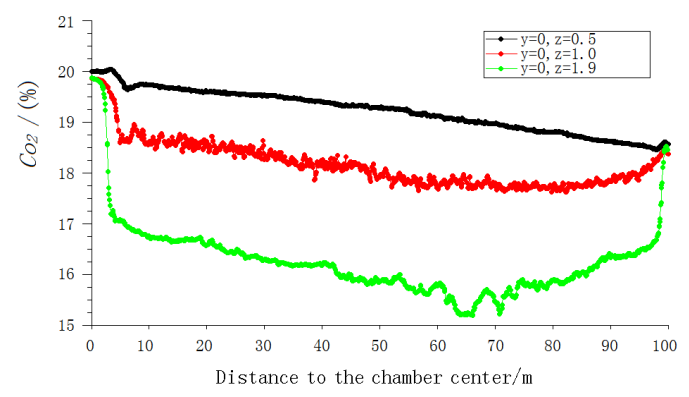

Fig.7. Oxygen content curves along x-direction line at different height from the tunnel floor.

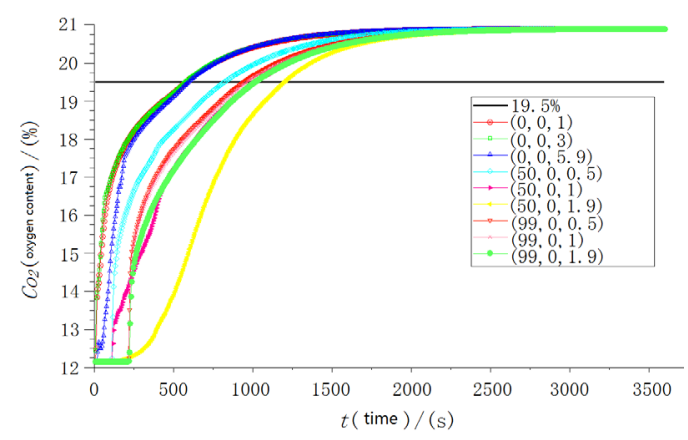

Fig.8. Oxygen content histories of different observation points as a function of time.

Fig.6 shows that oxygen content distribution law is the same with the airflow velocity distribution during the ventilation process. The oxygen content in the chamber recovers rapidly and distributes evenly. However, the oxygen distribution of the cross section in the tunnel is different. The oxygen content is high at the bottom of the chamber and is low at the top. In Fig.7, oxygen content along the $\mathrm{x}$-direction line $0.5 \mathrm{~m}$ height from the floor presents linear decrease. The oxygen content decreases and then increases with the increase of the height from the floor. Especially along the line $\mathrm{Z}=1.9 \mathrm{~m}, 65 \mathrm{~m}$ meters from the chamber, the oxygen content is the lowest $(15.2 \%)$. The distribution of 
oxygen content along the line illustrates that the thermal lift of the original hot air in the pipe tunnel affects the distribution of flow field, and thereby affects the recovery of oxygen content. Fig. 8 shows that the recovery of the oxygen content is relatively fast at the beginning of the ventilation, and then gradually becomes slow till oxygen content returns to normal (20.9\%). After 10mins ventilation, the oxygen content at the observation point $(0,0,5.9)$ reaches $19.5 \%$ (value below this is hypoxia). And 40mins later, it reaches $20.9 \%$. The recovery of the oxygen content at the observation point $(50,0,1.9)$ in the middle part of the pipe tunnel is slow. It takes 20 mins to reach $19.5 \%$ and 40 mins to reach $20.9 \%$. It can be concluded that even though the recovery rate of oxygen content is different between the pipe tunnel and the chamber, the time it takes to reach the normal value $(20.9 \%)$ is almost the same.

\subsection{Distribution of carbon dioxide}

When ventilation volume flow rate is $6000 \mathrm{~m}^{3} \cdot \mathrm{h}^{-1}$, carbon dioxide content contours of different cross sections after 10 mins ventilation in the chamber and the pipe tunnel are shown in Fig.9. Carbon dioxide content distributions along the tunnel of different heights are shown in Fig.10. Carbon dioxide content time histories of different observation points are shown in Fig. 11.

Fig.9 shows that carbon dioxide content is high at the top of pipe tunnel and is low at the bottom during the ventilation process, which is opposite to oxygen distribution. Fig.10 shows that carbon dioxide content at height $0.5 \mathrm{~m}$ away from the floor increases linearly along the tunnel. However carbon dioxide content increases at first and then decreases significantly with the increase of height from floor. In Fig.11, carbon dioxide content decreasing rate of each observation point in the chamber and the pipe tunnel is different, but the time it takes to reach the normal value of each observation point is the same. Furthermore, carbon dioxide recovery time and oxygen recovery time is the same.

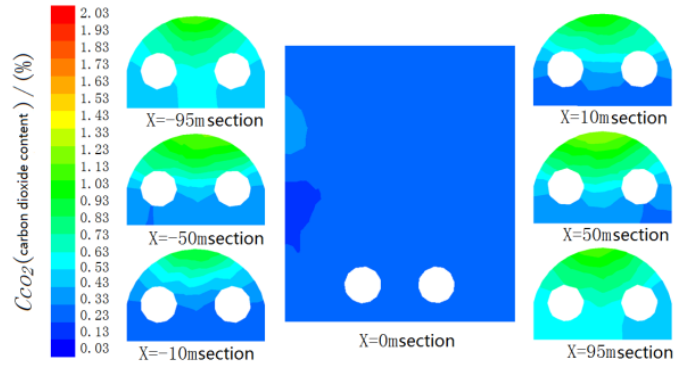

Fig.9. Carbon dioxide content contours of different cross sections along the tunnel.

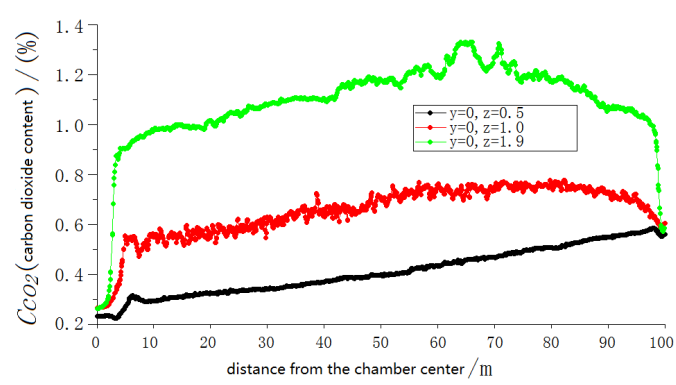

Fig.10. Carbon dioxide content curves along x-direction line at different height from the tunnel floor.

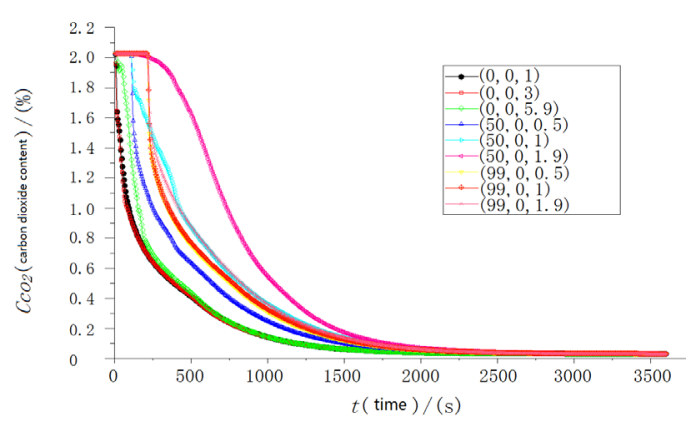

Fig.11. Carbon dioxide content histories of different observation points as a function of time.

\subsection{Influence of the ventilation volume flow rate on the ventilation effect}

In order to study change of temperature, oxygen, carbon dioxide along with time, the ventilation processes of different volume flow rate $\left(6000 \mathrm{~m}^{3} \cdot \mathrm{h}^{-1}, 8000 \mathrm{~m}^{3} \cdot \mathrm{h}\right.$ ${ }^{1}, 10000 \mathrm{~m}^{3} \cdot \mathrm{h}^{-1}, 12000 \mathrm{~m}^{3} \cdot \mathrm{h}^{-1}$ and $\left.14000 \mathrm{~m}^{3} \cdot \mathrm{h}^{-1}\right)$ are simulated. The observation point V6 $(50,0,1.9)$ is selected to analyze, because at this point, the decrease of the temperature as well as the recovery of carbon dioxide and oxygen is slow. The temperature, carbon dioxide and oxygen content time histories are shown in Fig.12, Fig.13 and Fig.14 respectively. 


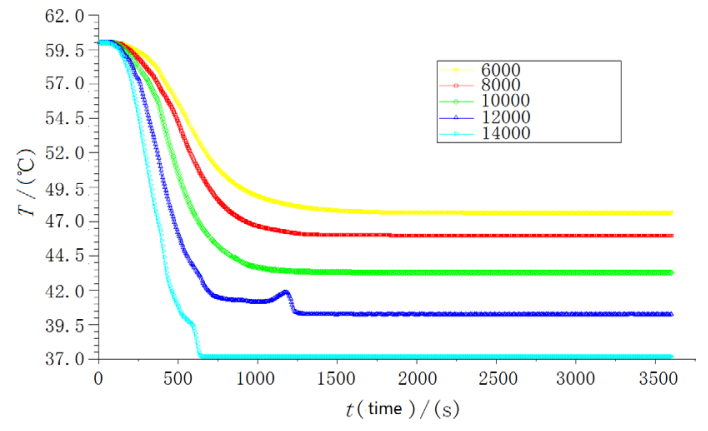

Fig.12. Temperature histories of different ventilation flow rate as a function of time.

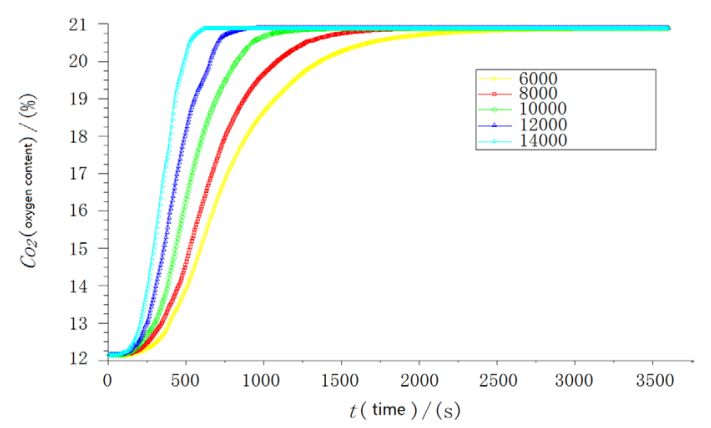

Fig.13. Oxygen content histories of different ventilation flow rate as a function of time.

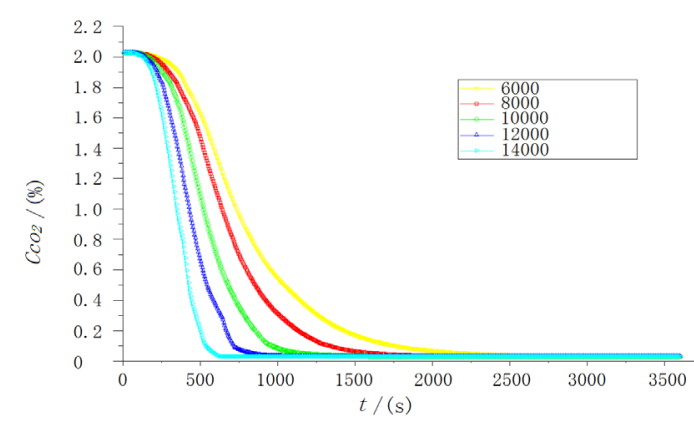

Fig.14. Carbon dioxide content histories of different ventilation flow rate as a function of time.

As can be seen from Fig.12, with the increase of ventilation flow rate, temperature in the tunnel decreased more quickly, and the final temperature is lower. In this heating confined space, when the ventilation flow rate is set as $6000 \mathrm{~m}^{3} \cdot \mathrm{h}^{-1}, 8000 \mathrm{~m}^{3} \cdot \mathrm{h}^{-1}$, $10000 \mathrm{~m}^{3} \cdot \mathrm{h}^{-1}, 12000 \mathrm{~m}^{3} \cdot \mathrm{h}^{-1}$ and $14000 \mathrm{~m}^{3} \cdot \mathrm{h}^{-1}$, it will take 25 mins, 18 mins, 15 mins, 12 mins and 10 mins respectively to reach steady state, and the final temperature is $48{ }^{\circ} \mathrm{C}, 46{ }^{\circ} \mathrm{C}, 43{ }^{\circ} \mathrm{C}, 40^{\circ} \mathrm{C}$ and $37{ }^{\circ} \mathrm{C}$ respectively. Fig.13 and Fig.14 show that time of oxygen to reach normal content is the same with time of carbon dioxide to reach normal content. That is, in the process of ventilation, it will take the same of time of low content gas recovery and high content of gas decreased. In this heating confined space, recovery time of all simulated gas of the several ventilation volume flow rate are $45 \mathrm{mins}, 32 \mathrm{mins}, 22 \mathrm{mins}, 15 \mathrm{mins}$ and 10mins respectively. Considering time to reach stale temperature, recovery time of oxygen content and carbon dioxide, the internal temperature of steady state and so on, when setting the ventilation volume flow rate as $6000 \mathrm{~m}^{3} \cdot \mathrm{h}^{-1}, 8000 \mathrm{~m}^{3} \cdot \mathrm{h}^{-1}, 10000 \mathrm{~m}^{3} \cdot \mathrm{h}^{-1}, 12000 \mathrm{~m}^{3} \cdot \mathrm{h}^{-1}$ and $14000 \mathrm{~m}^{3} \cdot \mathrm{h}^{-1}$, the ventlilation time should not be less than $45 \mathrm{mins}$, $32 \mathrm{mins}$, $22 \mathrm{mins}, 15 \mathrm{mins}$ and $10 \mathrm{mins}$ respectively.

\section{Conclusion}

- Because CFD numerical simulation method can reflect the process of ventilation intuitively and comprehensively, it can be used to simulate the process of ventilation in confined space. And the result can provide theoretical and technical supports for actual works.

- Distributions of the airflow fields during ventilation are affected by both the internal structures and the temperature fields in the municipal heating confined space. With the effect of the two factor, air flows fast at the bottom of pipe tunnel and slow at the top.

- Distributions of the airflow fields and the temperature fields can affect each other during the process of ventilation, which cause higher temperature at the top of the pipe tunnel and lower temperature at the bottom.

- Because time to reach normal oxygen content and time to reach normal carbon dioxide content is the same during ventilation, oxygen content can be used as the only index to evaluate ventilation effects. And it is better to use oxygen content close to the floor in the middle of trench as major parameter because recovery time is longer in the section.

- Ventilation times of municipal heating confined space should not be less than $45,32,22,15,10$ min when the ventilation volume flow rate are $6000,8000,10000,12000,14000 \mathrm{~m} 3 \cdot \mathrm{h}^{-1}$. Safety factor should be multiplied in practical application. 


\section{Analysis and Discussion}

More and more attention is paid to the municipal confined space work safety. Relevant laws and regulations are more and more perfect. And forced ventilation before entering confined space is an essential step. However, at present, the ventilation method and ventilation time are based on experience. The lack of theoretical basis not only affects the work efficiency, but also cannot guarantee the safety of the workers. In this paper, a numerical simulation method is used to simulate the process of forced ventilation in a heating confined space. The distribution of temperature, oxygen content and carbon dioxide content in the heating confined space is obtained. The recovery rules of internal temperature, oxygen and carbon dioxide under different ventilation conditions are further studied, and the optimal ventilation time of different air volume is determined. The research results can provide theoretical basis and technical support for the forced ventilation of heating confined space.

However, there are still some deficiencies in the research of this paper. The section size of the pipe, the length of the pipe tunnel, the setting position and the number of ventilation shaft will affect ventilation. The author will make further research in the future work.

\section{Acknowledgements}

This paper is supported by the Beijing Natural Science Foundation (No.8152014), Funding for postdoctoral scientific research activities in Beijing (No.2016ZZ-82).

\section{References}

1. OSHA, Permit-Required Confined Spaces. (Washington, 1998).

2. D.Burlet-Vienney, Y.Chinniah, A.Bahloul, et al.,Occupational safety during interventions in confined spaces,Safety Sci.79(2015)19-28.

3. 29 C.F.R., 1910.146, Permit-required Confined Spaces for General Industry. (Washington, D.C.,1993)

4. Government of United Kingdom, The Confined Spaces Regulations 1997. (1997).

5. Institut National de Rechercheet de Sécurité (INRS), Espacesconfinés - Guidepratique de ventilation $\mathrm{n} 8$, ED 703. Confined Spaces - Practical Guide For Ventilation $-n 8$. (INRS, Paris, 2010).

6. Standards Australia, Safe Working in a Confined Space. (Sydney, 2001).

7. NIOSH, Criteria for a Recommended Standard: Working in Confined Spaces. (DHHS Publication, Morgantown, 1979), pp.80-106.
8. NIOSH, Request for Assistance in Preventing Occupational Fatalities in Confined Spaces. (DHHS Publication, Morgantown, 1986),pp. 86-110.

9. NIOSH, A Guide to Safety in Confined Spaces. (DHHS Publication, Morgantown,1987), pp.87-113.

10. J.M.Gao, L.J.Wei. Studieson, Hazard Identification and Risk Control of Confined Space, Industrial Safety and Environmental Protection. 6(2005)63-54.

11. Y.H. Fan, S.K. Wang, G.C. Chen, et al., Prevention of Asphyxiation and Poisoning Accidents When Working in Confined Space, Jsafety Sci of China.16(5) (2006)89-93.

12. Y. Y. Zhong, The study on preventive measures of hydrogen sulfide poisoning accidents in confined working space.(Shanghai Jiao Tong University, shanghai, 2009).

13. B. Chen, H. L. Wang, J. F. Zhang, et al., Generating mechanism and control countermeasures of explosive gas in urban drainage limited space, Journal of Safety Science and Technology. 07(5) (2011)67-71.

14. E R Oviedo, D Johnson, H Shipley, Evaluation of hydrogen sulfide concentration and control in a sewer system, Environmental Technology.33(10-12) (2010)1207-1215.

15. J M Santos, V Kreim, J M Guillot, et al., An experimental determination of the $\mathrm{H}_{2} \mathrm{~S}$ overall mass transfer coefficient from quiescent surfaces at wastewater treatment plants, Atmospheric Environment. 60(11)(2012)18-24.

16. V Blanes-Vidal, M Guàrdia, X R Dai, et al., Emissions of $\mathrm{NH}_{3}, \mathrm{CO}_{2}$ and $\mathrm{H}_{2} \mathrm{~S}$ during swine wastewater management: Characterization of transient emissions after air-liquid interface disturbances, Atmospheric Environment. 54(2012) 408-418.

17. Li Mi, Study on explosion risk assessment and early warning mechanism of city sewers and septic tank gas. (Chongqing University, Chongqing, 2010).

18. Shujuan Peng. Study on risk assessment and early warning of gas explosion in the urban sewage pipeline in mountainous area. (Chongqing University, Chongqing, 2012).

19. Liang Bao. Development and application of the monitoring and early warning system of city sewer and septic tank combustible gas. (Chongqing University, Chongqing, 2009).

20. M.Siddiqui, S.Jayanti, T.Swaminathan, CFD analysis of dense gas dispersion in indoor environment for risk assessment and risk mitigation, $J$ Hazard Materials. 209-210(1) (2012):177-185.

21. S.G.Giannissi, V.Shentsov, D.Melideo, et al., CFD benchmark on hydrogen release and dispersion in confined, naturally ventilated space with one vent. Int J Hydrogen Energy. 40(5) (2015)2415-2429.

22. J.Zhao, Manbeck H B, Murphy D J, Computational Fluid Dynamics Simulations of Gas Evacuation and $\mathrm{O}_{2}$ Recovery Times for Fan-Ventilated Confined-Space Manure Pits, Studies in Foreign Education.51(6) (2008)2135-2149. 